\title{
Performance Investigation of Direct Evaporative Cooling in Major Cities of Iraq
}

\author{
Abdulrahman Th. Mohammad \\ Baqubah Technical Institute, Middle Technical University, Baghdad, Iraq
}

\begin{abstract}
The cities of Baghdad, Basrah, and Mousl are the major cities in the middle, southern and northern parts of Iraq, respectively. In this paper, TRNSYS model is investigated to study the performance of direct evaporative cooler (DEC) in these cities. Based on the hourly climate data of each month in Typical Meteorological Year (TMY), the period of $1^{\text {st }}$ of June to $31^{\text {th }}$ of August is used to estimate the performance of DEC in terms of evaporative supply temperature and cooling capacity. The simulation results show that the performance of DEC is capable of providing comfort conditions in Baghdad and Mosul by lowering supply air dry bulb temperature below the design condition $\left(24^{\circ} \mathrm{C}\right)$ up to $2^{\circ} \mathrm{C}$ in $\mathrm{June}$ and July and $1.5^{\circ} \mathrm{C}$ in August. In addition, the maximum cooling capacity of DEC is obtained in July about (3617, 3417 and 3160) kW for Baghdad, Mosul and Basrah, respectively.
\end{abstract}

Keywords: Evaporative cooling, cooling capacity, TRNSYS

\section{Introduction}

Air conditioning identifies the conditioning of air for maintaining specific conditions of temperature, humidity, and dust level inside an enclosed space [1]. Direct evaporative cooler (DEC) is a simple air-conditioning system widely used in dry and hot regions. Many studies have dealt with the performance of direct evaporative cooling. In India, Kulkarni and Rajput [2] made a theoretical performance analysis of direct evaporative cooling. Different materials were used in the analysis. The results of the analysis showed that the aspen fiber material had the highest efficiency of $87.5 \%$, while the rigid cellulose material had the lowest efficiency at $77.5 \%$. The outlet temperature and cooling capacity varied between $28.8^{\circ} \mathrm{C}$ to $26.5^{\circ} \mathrm{C}$ and $13408 \mathrm{KJ} / \mathrm{h}$ to $56686 \mathrm{KJ} / \mathrm{h}$ for the two materials, respectively. Kachhwaha and Suhas [3] designed, fabricated, and predicted the performance of an evaporative medium. The pad thickness and height were achieved for maximum cooling. Chenguang and Agwu [4] evaluated the effect of speed and the dry-bulb temperature of frontal air, and the temperature of the incoming water on cooling performance of a direct evaporative cooling combined with a wetted medium. The results of the analysis showed that direct evaporative cooling efficiency decreased with frontal air velocity and incoming water

${ }^{*}$ Corresponding author. Tel.: +9647723482910

E-mail: abd20091976@gmail.com

(C) 2015 International Association for Sharing Knowledge and Sustainability

DOI: $10.5383 /$ ijtee.10.02.013 temperature, and increased with frontal air dry-bulb temperature. A simplified mathematical model was used by [5] to discuss the heat and mass transfer between the air and water in a direct evaporative cooler. The results indicate that during a steady state condition, the cooling efficiency is decreased by increasing the inlet frontal air velocity, and increased by increasing the pad thickness. This is because the contact surface between water and air is increased. Moien et al. [6] studied a two-stage cooling system that consisted of a nocturnal radiative unit, a cooling coil, and an indirect evaporative cooler in weather conditions for the city of Tehran. The results showed that the first stage of the system increased the effectiveness of the indirect evaporative cooler. Dai and Sumathy [7] developed a mathematical model to predict the interface temperature of falling film in a cross-flow direct evaporative cooler. Analysis results indicated that the system performance could be improved by optimizing the mass flow rates of the feed water and processed air, as well as the different dimensions of the pad. Wu et al.[8] proposed a simplified cooling efficiency based on the energy balance analysis of air to analyze the heat and mass transfer between air and water film in the direct evaporative cooler. The analysis showed that the frontal air velocity and thickness of the pad module are two key factors influencing the cooling efficiency of a direct evaporative cooler. A model of the dew point evaporative cooling system was developed by [9] to simulate 
the heat and mass transfer processes under various inlet air conditions and the influence of major operating parameters. The model was used to optimize the system parameters and to investigate the system effectiveness when operating under various inlet air conditions. Abdulrahman et al. [10] evaluated experimentally the performance of the direct evaporative cooler in Malaysia. The experimental results show that the output temperature of the air varies between $27.5^{\circ} \mathrm{C}$ and $29.4^{\circ} \mathrm{C}$, while the cooling capacity is between $1.384 \mathrm{~kW}$ and $5.358 \mathrm{~kW}$. The main objective of this paper is to perform a TRNSYS simulation model for estimating the performance of direct evaporative cooler system in three different cities in Iraq.

\section{TRNSYS Model}

TRNSYS is quasi-steady states program consists of many components stored in a big library. TRNSYS enables system components interconnected graphically in the simulation studio in any desired manner to construct a system's model. In order to facilitate the selection of the system components, it is important to develop an information flow diagram. The information flow diagram of DEC system model is shown in Fig.1. The descriptions of the main components of the model are represented in Table 1.

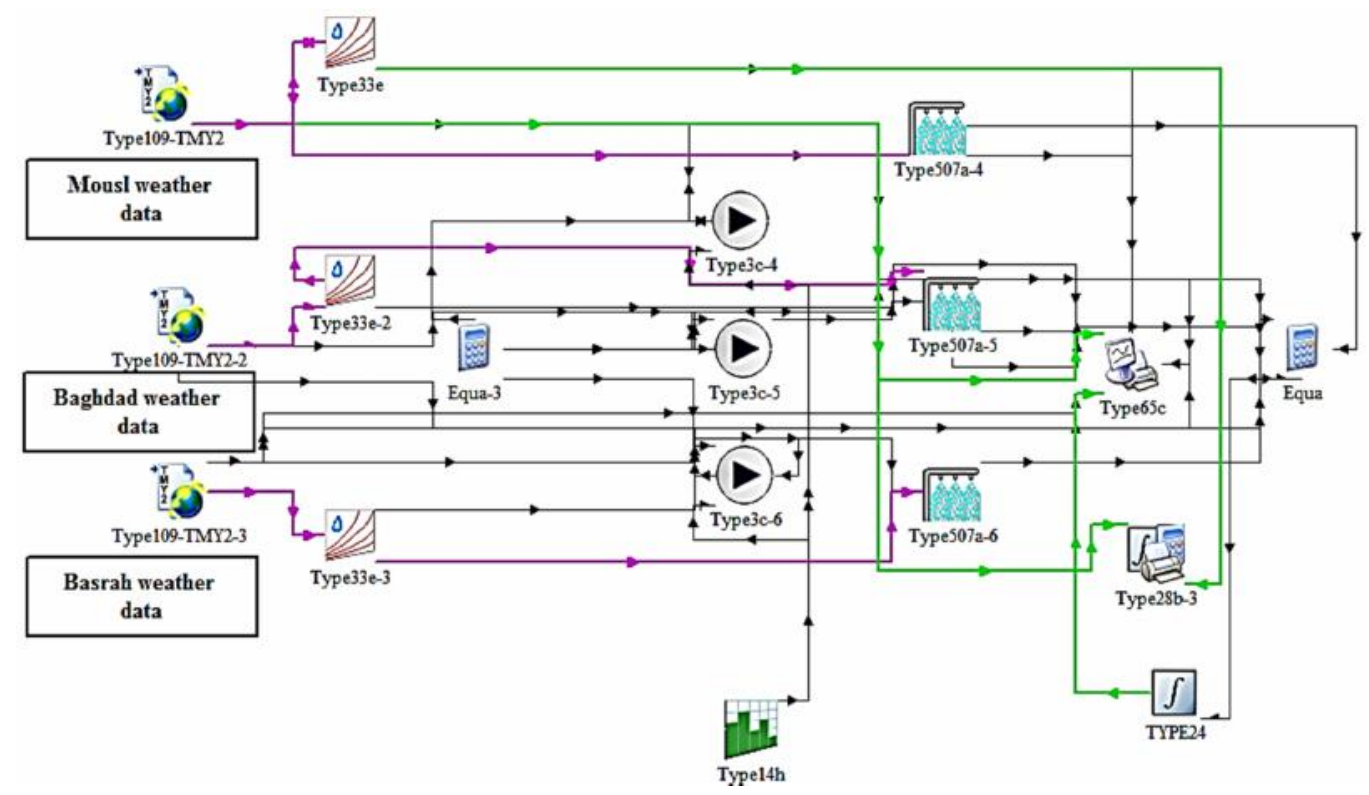

Fig.1 DEC system in TRNSYS module

Table 1 Components description of the TRNSYS model

\begin{tabular}{cl}
\hline Component symbol & \multicolumn{1}{c}{ Description } \\
\hline Type 109-TMY2 & $\begin{array}{l}\text { This component reads weather data for different cities of the worlds in the library of TRNSYS at } \\
\text { regular time in the typical meteorological year (TMY) data }\end{array}$ \\
Type 33 e & $\begin{array}{l}\text { This component takes as input the dry bulb temperature and relative humidity of moist air and calls the } \\
\text { TRNSYS Psychrometrics routine, returning the following corresponding moist air properties: dry bulb } \\
\text { temperature, dew point temperature, wet bulb temperature, relative humidity, absolute humidity ratio, } \\
\text { and enthalpy }\end{array}$ \\
& $\begin{array}{l}\text { An evaporative cooling device for which the user supplies the inlet air conditions and a target air outlet } \\
\text { relative humidity. The outlet air dry bulb temperature is modulated given to achieve the desired outlet } \\
\text { relative humidity. The cooling process is assumed to be a constant wet bulb temperature process } \\
\text { meaning that air enters and exits at the same wet bulb temperature }\end{array}$ \\
& $\begin{array}{l}\text { A transient simulation, it is sometimes convenient to employ a time dependent forcing function which } \\
\text { has a behavior characterized by a repeated pattern. The pattern of the forcing function is established by } \\
\text { a set of discrete data points indicating the value of the function at various times throughout one cycle }\end{array}$ \\
Type $14 \mathrm{~h}$ & $\begin{array}{l}\text { Single speed fan } \\
\text { The online graphics component that used to display selected system variables while the simulation is }\end{array}$ \\
Type $65 \mathrm{c}$ & $\begin{array}{l}\text { Thogressing } \\
\text { The component that integrated a series of quantities over a period of time }\end{array}$ \\
Type 24 & Online plotter and simulation summary
\end{tabular}




\section{Weather data of cities}

From the hourly climate data in Typical Meteorological Year (TMY) and for the period of $1^{\text {st }}$ of June to $31^{\text {th }}$ of August, the air wet bulb temperature and humidity ratio at the maximum dry bulb temperature in three cities are summarized in Table 2, Figs. 2 and 3.

\section{Results and discussion}

\subsection{Evaporative cooler temperature}

Fig.4 shows variations of ambient temperature $\left(\mathrm{T}_{\mathrm{am}}\right)$, wet bulb temperature $\left(\mathrm{T}_{\mathrm{w}}\right)$ and supply air temperature of evaporative cooler $\left(\mathrm{T}_{\text {evap }}\right)$ with time under the air flow rate of $0.27 \mathrm{~kg} / \mathrm{sec}$. The period of simulation is between $1^{\text {st }}$ of June and $31^{\text {th }}$ of August. The time changes from 3624 to 5832, which is totally 2208 hours. As shown in the figure, the variation of supply air temperature of DEC in Mosul, Baghdad and Basrah is drawn by blue, orange and sky-blue color respectively. From Figure $5 \mathrm{a}$, the maximum drop temperature of the supply air in Baghdad city is $19^{\circ} \mathrm{C}, 21.75^{\circ} \mathrm{C}$ and $19.75^{\circ} \mathrm{C}$ in June, July and
August respectively. In Mosul city, the maximum drop temperature is recorded as $18.5^{\circ} \mathrm{C}, 20^{\circ} \mathrm{C}$ and $19.5^{\circ} \mathrm{C}$ in June, July and August respectively (Fig.5b), while in Basrah city recorded around $22.5^{\circ} \mathrm{C}$ in three months (Fig. 5c). The results show that the performance of DEC is capable of providing comfort conditions in Baghdad and Mosul by lowering supply air dry bulb temperature below the design condition temperature $\left(24^{\circ} \mathrm{C}\right)$ up to $2^{\circ} \mathrm{C}$ in June and July and $1.5^{\circ} \mathrm{C}$ in August. In the otherwise, the supply air temperature of DEC in Basrah city is more than the design condition temperature by (1.5 to 2$)^{\circ} \mathrm{C}$. The reason may be explained as follows. Basrah city located in regions with high wet-bulb temperature that the direct systems do not provide comfort conditions.

\subsection{Cooling capacity}

Fig.6 shows the integration of cooling capacity of DEC system in June, July and August. As shown in the figure, the maximum cooling capacity of Baghdad city is about $3617 \mathrm{~kW}$ in July and minimum in August about $3427 \mathrm{~kW}$. While the maximum and minimum cooling capacity of Mosul city is about $3417 \mathrm{~kW}$ in July and $2986 \mathrm{~kW}$ in June respectively. In Basrah city, the cooling capacity changes from $2790 \mathrm{~kW}$ in June, 3160 kW in July and 3016 kW in August.

Table 2 Summarizes of weather data in three cities

\begin{tabular}{cccccccccc}
\hline City & \multicolumn{3}{c}{ June } & \multicolumn{3}{c}{ July } & \multicolumn{3}{c}{ August } \\
\cline { 2 - 9 } & $\begin{array}{c}\text { Tam } \\
\left({ }^{\circ} \mathrm{C}\right)\end{array}$ & $\begin{array}{c}\text { Tw } \\
\left({ }^{\circ} \mathrm{C}\right)\end{array}$ & $\begin{array}{c}\mathrm{Wa} \\
(\mathrm{g} / \mathrm{kg}\end{array}$ & $\begin{array}{c}\text { Tam } \\
\left({ }^{\circ} \mathrm{C}\right)\end{array}$ & $\begin{array}{c}\mathrm{Tw} \\
\left({ }^{\circ} \mathrm{C}\right)\end{array}$ & $\begin{array}{c}\mathrm{Wa} \\
(\mathrm{g} / \mathrm{kg}\end{array}$ & $\begin{array}{c}\text { Tam } \\
\left({ }^{\circ} \mathrm{C}\right)\end{array}$ & $\begin{array}{c}\mathrm{Tw} \\
\left({ }^{\circ} \mathrm{C}\right)\end{array}$ & $\begin{array}{c}\mathrm{Wa} \\
(\mathrm{g} / \mathrm{kg} \\
\left.\mathrm{H}_{2} \mathrm{O}\right)\end{array}$ \\
\hline Baghdad & 41 & 21 & 9.1 & 44 & 21 & 9.5 & 42.5 & 22 & 9.1 \\
Mosul & 40.5 & 20.5 & 9.5 & 43.5 & 21 & 11.2 & 42 & 22 & 10.2 \\
Basrah & 47 & 23.5 & 11 & 48.5 & 25 & 12.5 & 47.5 & 25 & 13.1 \\
\hline
\end{tabular}

Tam: air dry bulb temperature $\left({ }^{\circ} \mathrm{C}\right)$, Tw: air wet bulb temperature $\left({ }^{\circ} \mathrm{C}\right)$, Wa: air humidity ratio $\left(\mathrm{g} / \mathrm{kg} \mathrm{H} \mathrm{H}_{2} \mathrm{O}\right)$

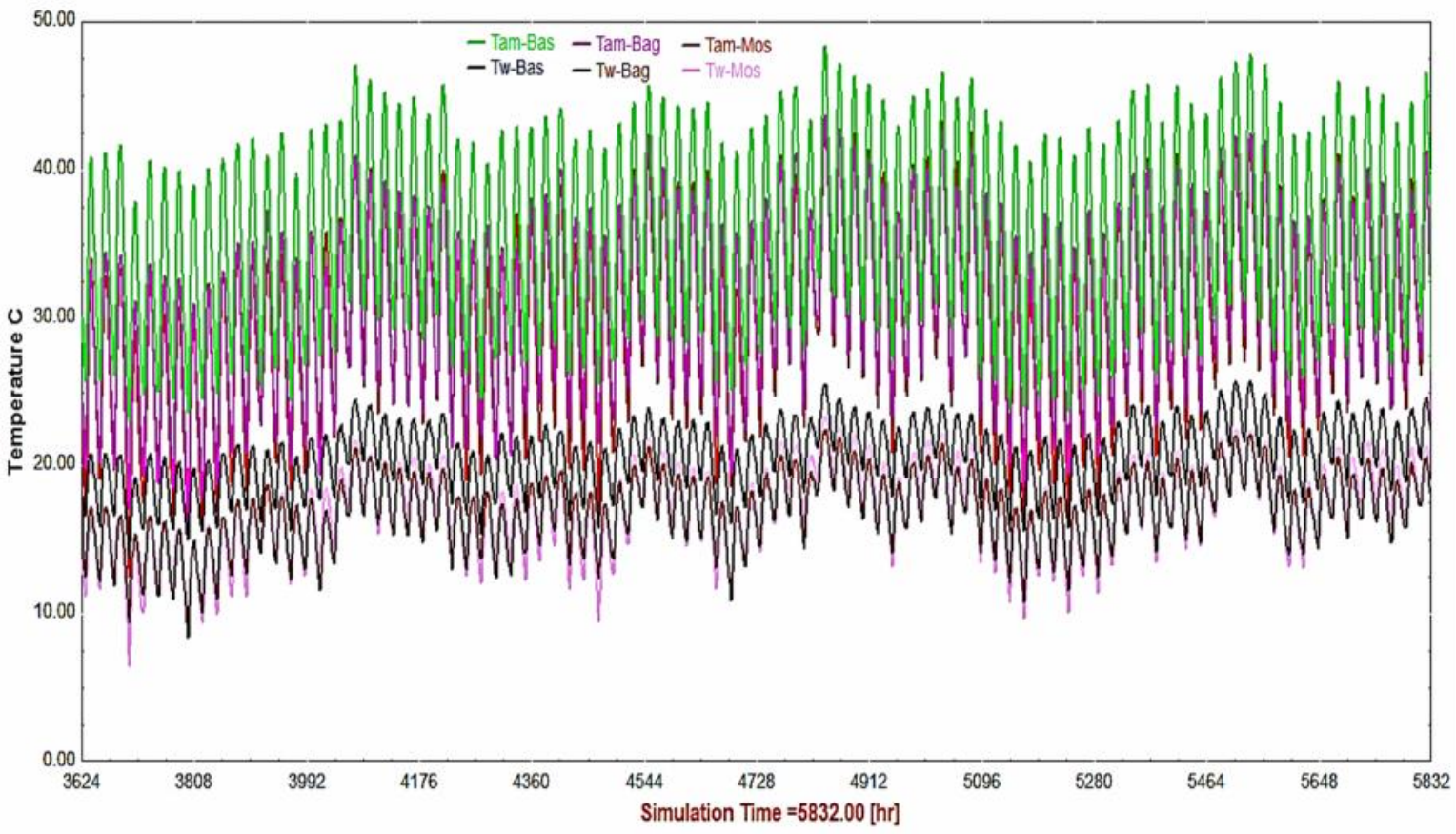

Fig.2 Ambient and wet bulb temperatures of three cities 


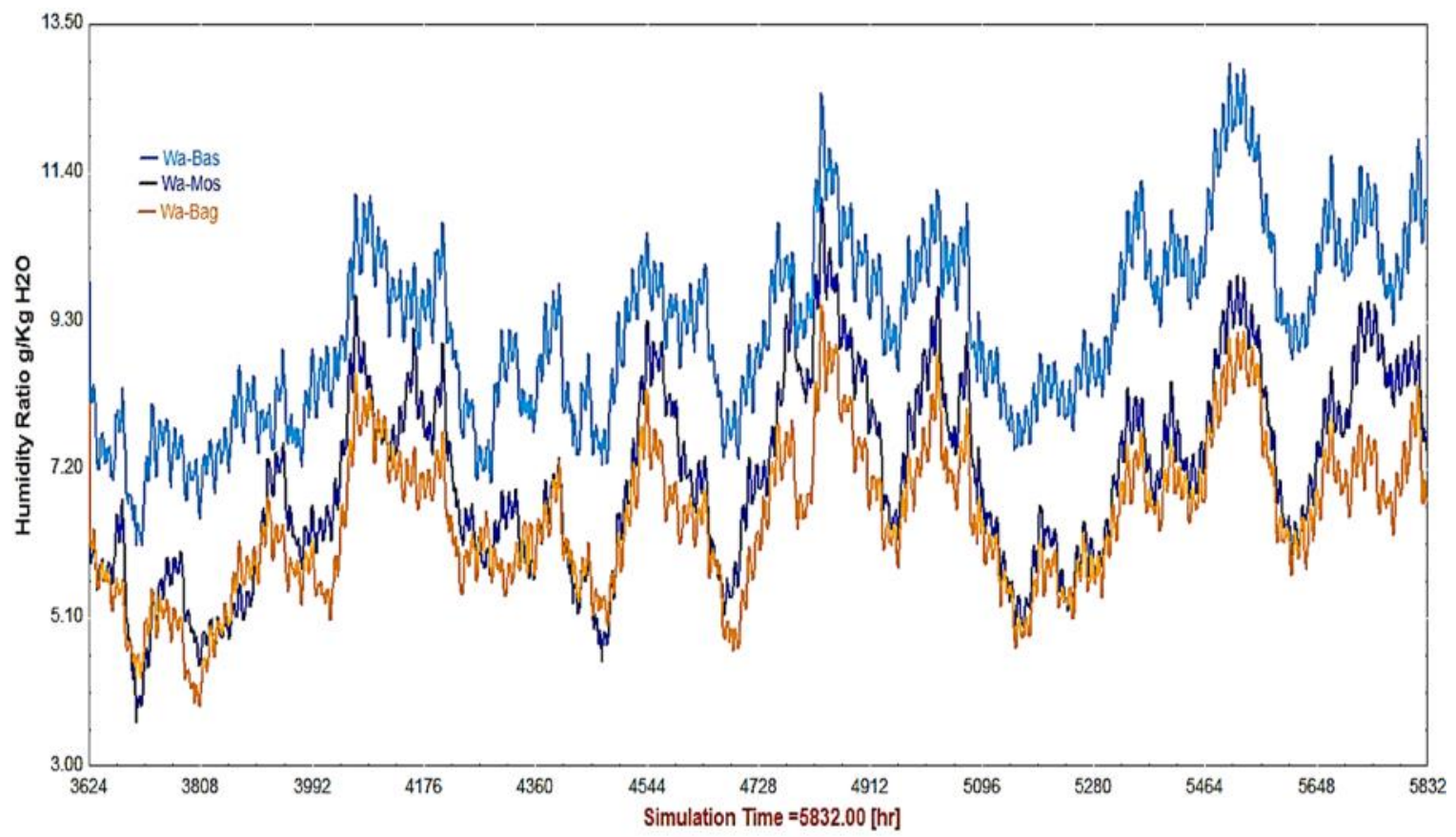

Fig.3 Humidity ratio of three cities

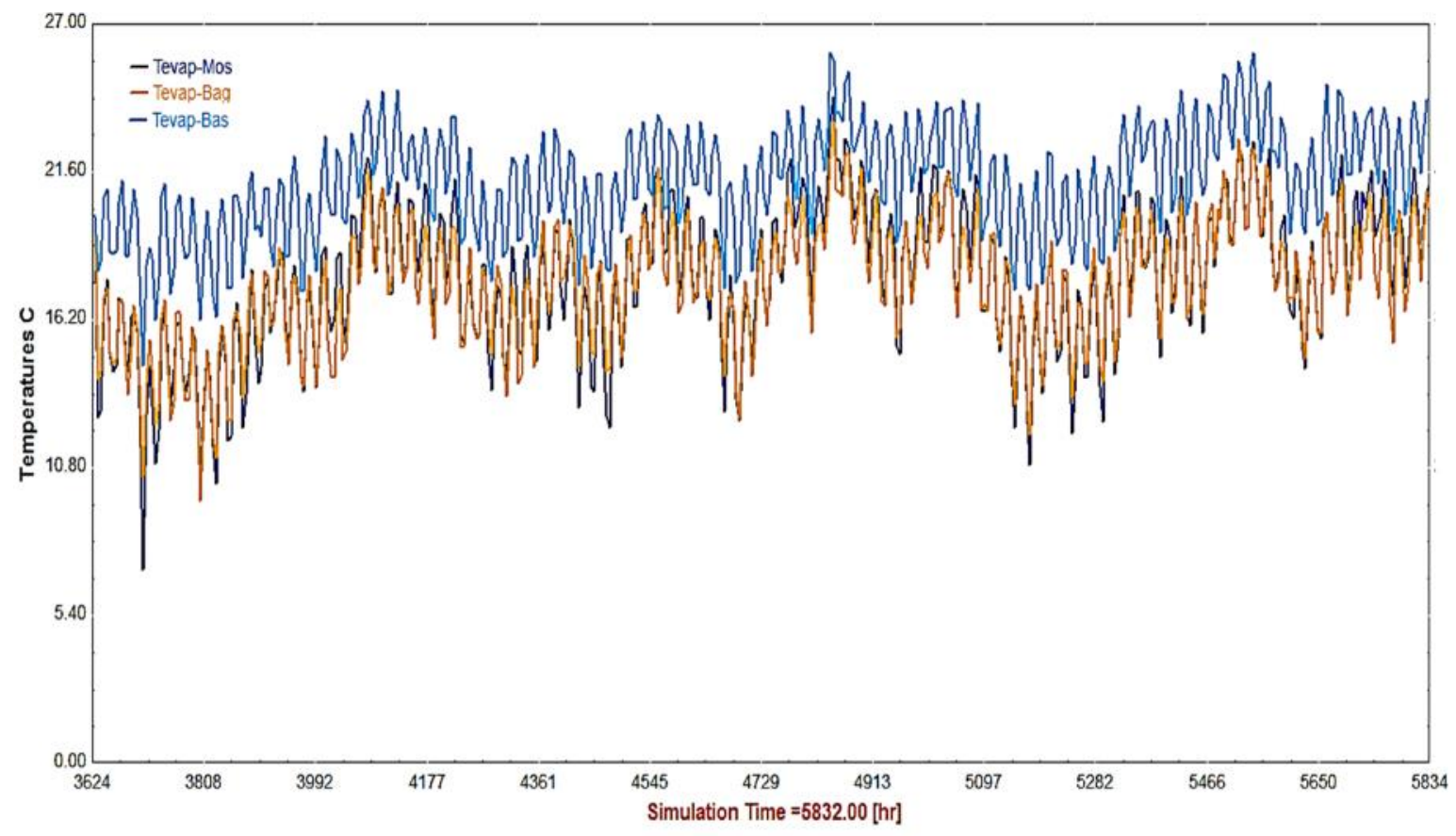

Fig.4 Ambient, wet bulb and evaporative cooler temperatures of three cities 


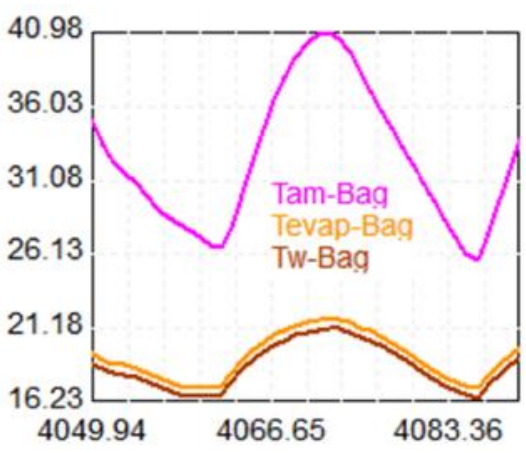

(a) June-Baghdad

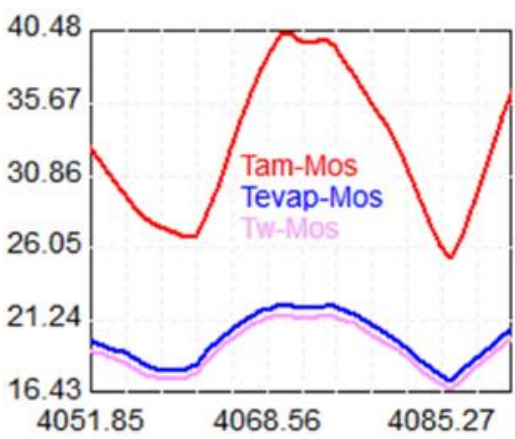

(d) June -Mosul

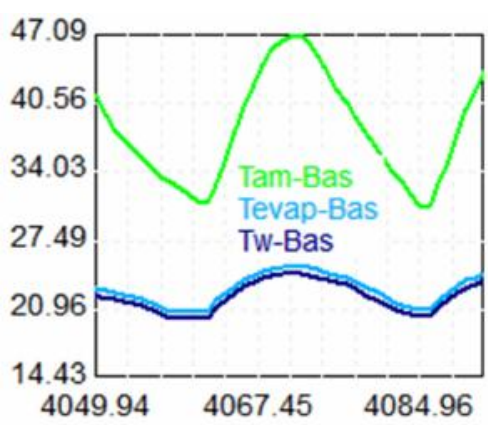

(g) June-Basrah

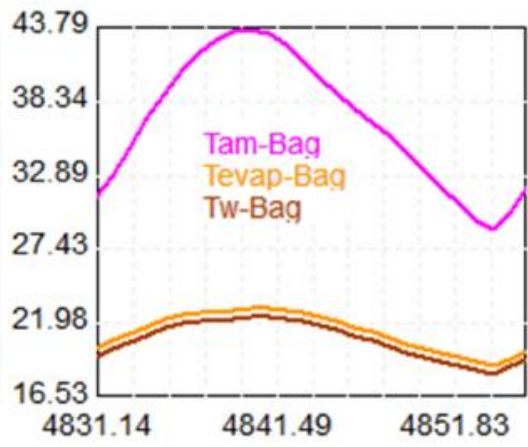

(b) July-Baghdad

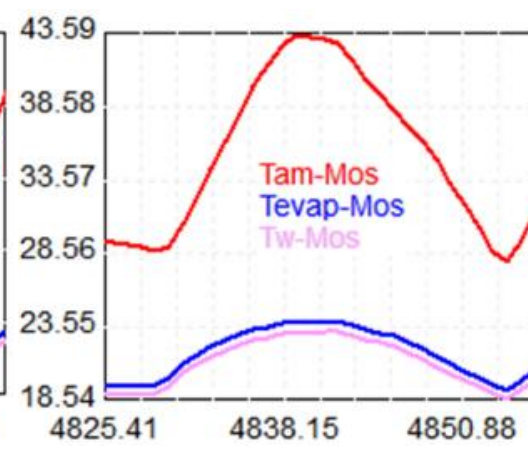

(e) July-Mosul

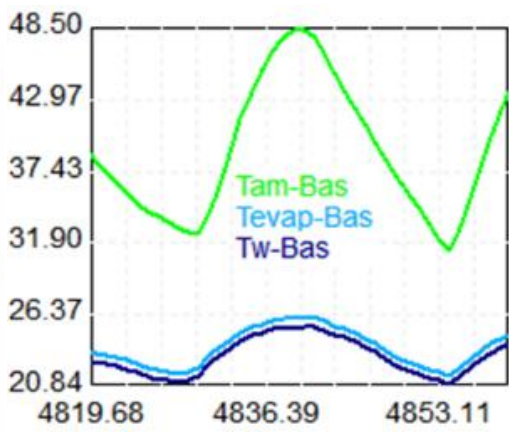

(h) July- Basrah

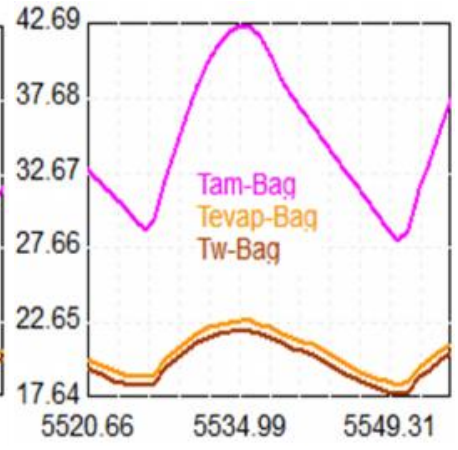

(c) August-Baghdad

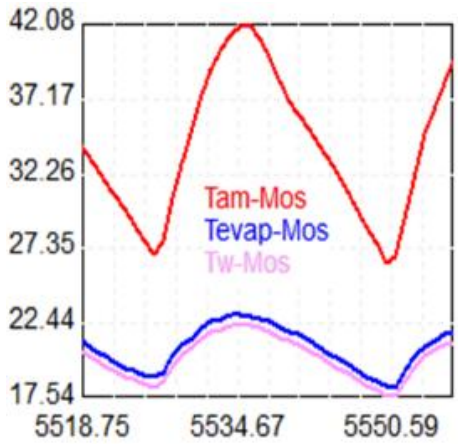

(f) August-Mosul

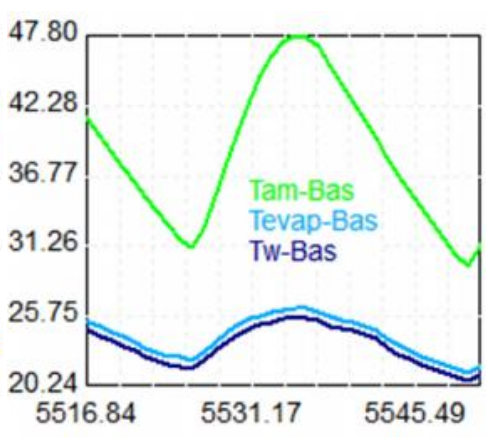

(i) August- Basrah

Fig. 5 Ambient, wet bulb and evaporative cooler temperatures of three cities in details 


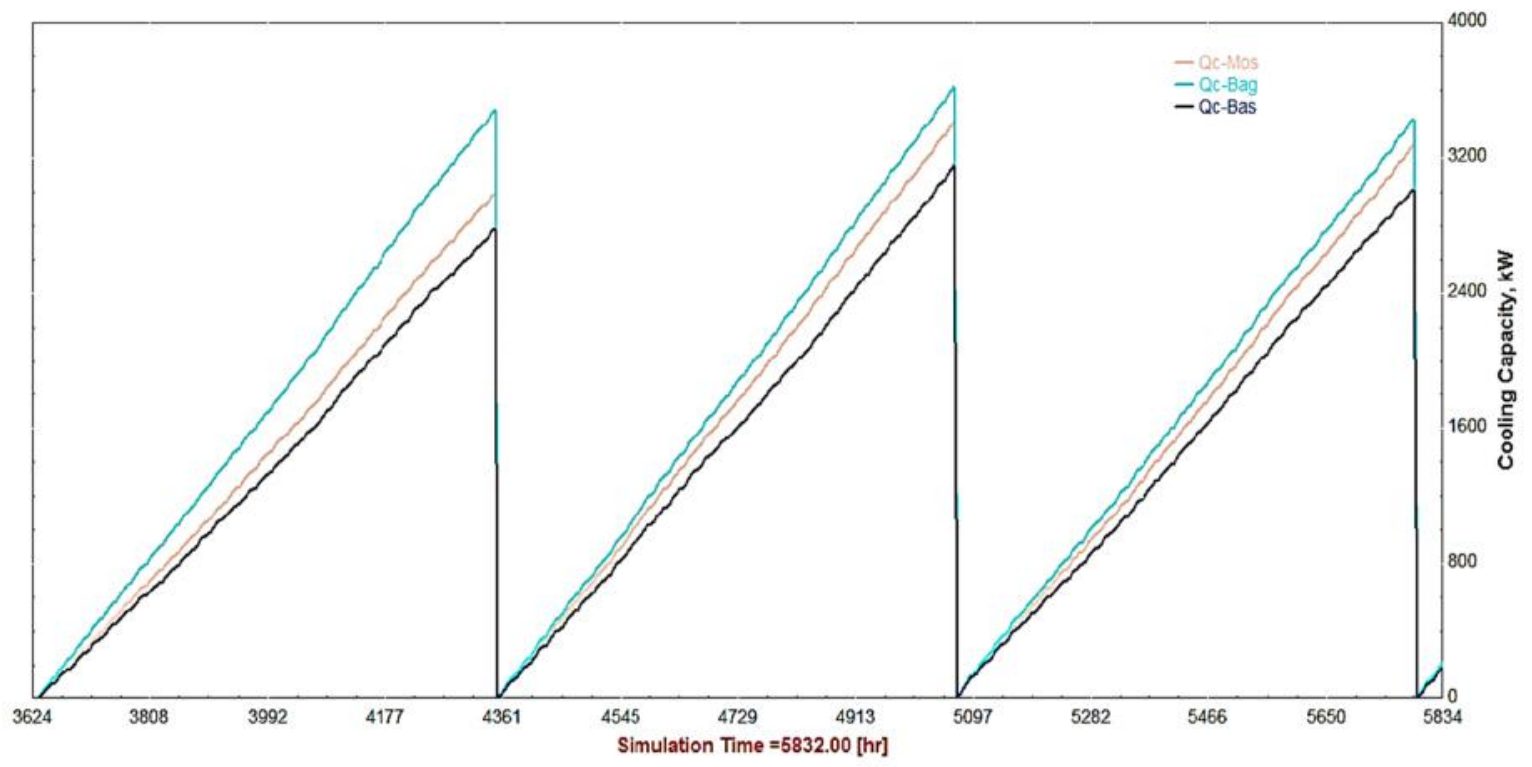

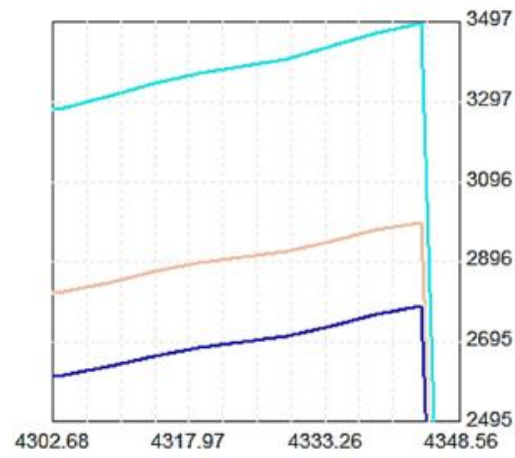

(a) June

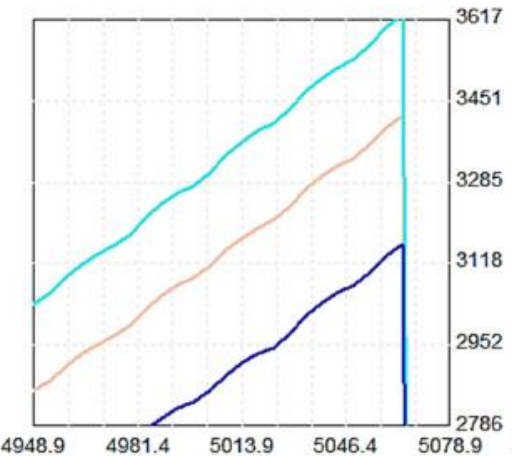

(b) July

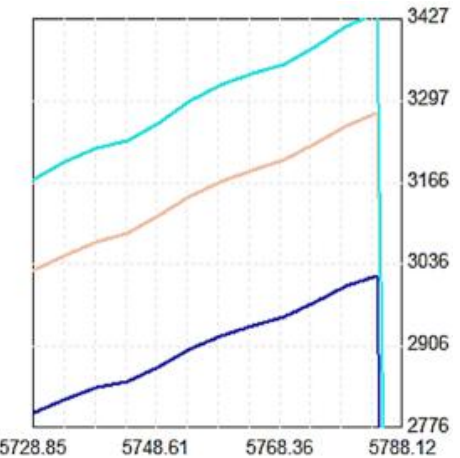

(c) August

Fig.6 Integration of cooling capacity of three cities in June, July and August

\section{Conclusion}

The performance of direct evaporative cooler has been investigated for conditions in the major cities of Iraq. TRNSYS model is proposed for estimating the evaporative air supply temperature and cooling capacity of DEC.

Based on the simulation results, the performance of DEC is capable of providing comfort conditions in Baghdad and Mosul by lowering supply air dry bulb temperature below the design condition $\left(24^{\circ} \mathrm{C}\right)$ up to $2^{\circ} \mathrm{C}$ in June and July and $1.5^{\circ} \mathrm{C}$ in August.

In addition, the maximum cooling capacity of DEC is obtained in July about 3617, 3417 and $3160 \mathrm{~kW}$ for Baghdad, Mosul and Basrah, respectively.

\section{Acknowledgments}

The authors are grateful to the staff of Baqubah Technical Institute / Middle Technical University-Iraq for their help.

\section{References}

[1] Essam E. Kkalil., "Energy-Efficiency in Air Conditioned Buildings: The Green Buildings Dream" Int. J. of Thermal \& Environmental Engineering, vol. 2, pp.9-18, 2011.

[2] Kulkarni R. K. and Rajput S. P.S., "Comparative performance of evaporative cooling pads of alternative materials," IJAEST, vol. 10, pp. 239244, 2011.

[3] Kachhwaha S. S. and Suhas P, "Heat and mass transfer in direct evaporative cooler" J. Sci. Ind. Res. Vol. 69, 705-710, 2010.

[4] Chenguang S. and Agwu N., "Empirical correlation of Cooling efficiency and transport phenomena of direct evaporative cooler" Appl. Therm. Eng. Vol. 40, pp. 48-55, 2012.

[5] Fouda A. and Z. Melikyan, "A simplified model for analysis of heat and mass transfer in a direct evaporative cooler" Appl. Therm. Eng., vol. 31, pp.932-936,2011. 
[6] Moien F., Ghassem H. and Shahram D, "A twostage System of nocturnal radiative and indirect evaporative cooling for conditions in Tehran," Energy Build, vol. .42, pp. 2131-2138, 2010.

[7] Y.J. Dai and K. Sumathy, "Theoretical study on across-flow direct evaporative cooler using honeycomb paper as packing material" Appl. Therm. Eng, vol. 22, pp. 1417-1430, 2002.

[8] J.M. Wu, X. Huang and H. Zhang, "Theoretical analysis on heat and mass transfer in a direct evaporative cooler," Appl. Therm. Eng. Vol. 29, pp.980-984,2009.
[9] B. Riangvilaikul and S. Kumar, " Numerical study of a novel dew point evaporative cooling System," Energy and Buildings, vol. 42, pp. 2241-2250, 2010 .

[10] Abdulrahman Th. Mohammad, Sohif B. M., M.Y. Sulaiman, K. Sopian and Abduljalil A. A, "Experimental Performance of a Direct Evaporative Cooler Operating in Kuala Lumpur," Int. J. of Thermal \& Environmental Engineering, vol. 6, pp. $15-20,2013$. 